\title{
Antibiotic Susceptibility Patterns of Bacterial Isolates from Routine Clinical Specimens from Referral Hospitals in Tanzania: A Prospective Hospital-Based Observational Study
}

This article was published in the following Dove Press journal:

Infection and Drug Resistance

\section{Nicholaus P Mnyambwa' \\ Coline Mahende' \\ Amani Wilfred' \\ Erica Sandi ${ }^{\prime}$ \\ Nicodem Mgina ${ }^{2}$ \\ Clara Lubinza' \\ Amos Kahwa' \\ Pammla Petrucka $\left(\mathbb{D}^{3,4}\right.$ \\ Sayoki Mfinanga $\mathbb{D}^{1,3,5}$ \\ Esther Ngadaya (iD) \\ Godfather Kimaro'}

'National Institute for Medical Research, Muhimbili Research Centre, Dar es Salaam, Tanzania; ${ }^{2}$ Central Tuberculosis Reference Laboratory (CTRL), Dar es Salaam, Tanzania; ${ }^{3}$ School of Life Science and Bioengineering, Nelson Mandela African Institution of Science and Technology, Arusha, Tanzania; ${ }^{4}$ University of Saskatchewan, Saskatoon, Canada;

${ }^{5}$ Department of Epidemiology and Statistics, Muhimbili University of Health and Allied Sciences, Dar es Salaam, Tanzania
Correspondence: Nicholaus P Mnyambwa National Institute for Medical Research Muhimbili Research Centre, P. O. Box 447, Dar es Salaam, Tanzania Email lodnicho@gmail.com
Introduction: Antimicrobial resistance is one of the biggest threats of modern public health. Although sub-Saharan Africa is highly burdened with infectious diseases, current data on antimicrobial resistance are sparse.

Methods: A prospective study was conducted between October 2018 and September 2019 to assess the antibiotic susceptibility patterns of clinical bacterial isolates obtained from four referral hospitals in Tanzania. We used standard media and Kirby-Bauer disc diffusion methods as per Clinical and Laboratory Standards Institute (CLSI) standards.

Results: We processed a total of 2620 specimens of which 388 (14.8\%) were culturepositive from patients with a median (IQR) age of $28(12-44)$ years. Of the positive cultures, $52.3 \%$ (203) were from females. Most collected specimens were ear pus 28.6\% (111), urine $24.0 \%$ (93), wound pus 20.6\% (80), stool 14.9\% (58), and blood 8.3\% (32). Predominant isolates were $S$. aureus $28.4 \%$ (110), E. coli 15.2\% (59), P. aeruginosa 10.6\% (41), P. mirabilis $7.0 \%$ (27), V. cholerae 01 Ogawa 6.2\% (24), Klebsiella spp. 5.2\% (20) and Streptococcus spp. 4.6\% (18). Generally, the isolates exhibited a high level of resistance to commonly used antibiotics such as Ampicillin, Amoxicillin-Clavulanic acid, Erythromycin, Gentamicin, Tetracycline, Trimethoprim, third-generation Cephalosporins (Ceftriaxone and Ceftazidime), and reserved drugs (Clindamycin and Meropenem). S. aureus isolates were resistant to most of the antibiotics tested; $66.7 \%$ were classified as MRSA infections.

Conclusion: Antibiotic resistance to commonly prescribed antibiotics was alarmingly high. Our findings emphasize the need for comprehensive national control programs to combat antibiotic resistance.

Keywords: antibiotics, antimicrobial resistance, AMR, antibiotic susceptibility testing, methicillin-resistant Staphylococcus aureus, MRSA, bacterial isolates

\section{Background}

Antimicrobial resistance (AMR) has become a severe global health threat, especially in sub-Saharan Africa where the burden of infectious diseases is high. ${ }^{1}$ Common illnesses like pneumonia, diarrhea, sexually transmitted infections, postoperative infections, and tuberculosis are increasingly becoming untreatable. ${ }^{2}$ Patients infected with drug-resistant pathogens are at increased risk of unfavorable clinical outcomes and consume more health-care resources than patients infected with non-resistant pathogen of the same type. ${ }^{3}$ Recent data shows that about 
700,000 death per year are attributable to AMR infections and projected to increase to 10 million annually by 2050 if the present trends persist. ${ }^{4}$ Clinically, the emergence of AMR is primarily driven by non-compliance with prescribed antimicrobials therapy, which in turn promotes spontaneous mutations in chromosome or control genes leading to new mutant pathogens with selective pressure in the presence of antimicrobials. ${ }^{5}$ Further accumulation of such beneficial mutations catalyzes the evolution of multidrug-resistant strains, ${ }^{6}$ which necessitate the use of broadspectrum antibiotics as the ultimate choice. Especially alarming is the emergence and spread of multi-drug resistant bacteria which are hard to treat with the available antibiotics. $^{2}$ This include the emergence and spread of extended-spectrum beta-lactamases (ESBL), АmpC betalactamases, and carbapenemase-producing Gram-negative bacteria (ie carbapenem-resistant EnterobacteriaceaeCRE) and Staphylococcus aureus (MRSA) which are rapidly increasing worldwide. ${ }^{7-9}$

In sub-Saharan Africa, AMR is mostly exacerbated by limited access to appropriate therapies, irrational use of antibiotics, and lack of clinical microbiology laboratories for drug susceptibility testing. ${ }^{1}$ Most infections are managed empirically using antibiotics which are mainly obtained over-the-counter without a proper prescription. At the level of public health systems, the situation is worsened by a lack of coordinated AMR surveillance and weak regulatory frameworks for the access and use of antibiotics. ${ }^{10}$ In addition, the emergence of resistant pathogens is aggravated by underlying illnesses, such as human immunodeficiency virus (HIV), which has promoted the utilization of antibiotics against opportunistic infections. ${ }^{11}$

Although bacterial infections particularly Gramnegative bacteria are among major causes of illness and death in sub-Saharan Africa, ${ }^{12,13}$ data on their antibiotic resistance remain scant due to limited disease detection and surveillance capacity. Prevalent bacterial infections include lower respiratory infections (pneumonia), diarrheal diseases, urinary tract infections, bloodstream infections (typhoid, sepsis, meningitis, and bacteremia), sexually transmitted infections (eg, gonorrhea), and healthcareassociated infections (eg, MRSA). ${ }^{12,13}$ A recent situation analysis on antibiotic use and resistance in Tanzania revealed a lack of national data representativeness for antibiotic resistance for common bacterial infections. ${ }^{14}$ The current study aimed to provide additional evidence on the resistance pattern of bacterial isolates to widely used antibiotics in Tanzania.

\section{Methodology \\ Study Design and Setting}

We conducted a hospital-based observational study between October 2018 -September 2019 involving four cross-border tertiary hospitals from four different regions in Tanzania. Such hospitals included: Maweni Regional Hospital in Kigoma Region, Musoma Regional Hospital in Mara Region, Sumbawanga Regional Hospital in Rukwa Region, and St. Benedict Ndanda Hospital (Masasi) in Mtwara Region (Figure 1). These hospitals were among satellite study sites for the East African Public Health Laboratory Network (EAPHLN) project and health facilities that form a surveillance system for monitoring crossborder disease outbreak dynamics in the country. The majority of inhabitants (80\%) reside in rural settings, practicing subsistence farming and informal trade.

Administrative boundary shapefile was obtained from the Tanzania National Bureau of Statistics.

\section{Data Collection}

Clinical specimens were collected from both outpatients and inpatients as part of each hospital's routine clinical care. Thus, specimens were requested based on clinicians' assessment and then submitted for microbiological tests.

\section{Laboratory Procedure}

Specimen processing, identification of organisms to the genus and/or species level, and in-vitro antibiotic susceptibility testing were performed in accordance with the standard microbiological procedures and the CLSI guidelines. ${ }^{15}$ Pathogenic bacteria were identified using standard microbiological methods such as morphology on culture media, gram staining, and conventional biochemical tests. In case of ambiguity, the analytical profile index (API ${ }^{\mathrm{TM}}$ ) biochemical test kit (BioMérieux, France) and/or serological tests (antisera for $V$. cholerae) were used to confirm identification. In-vitro antibiotic susceptibility testing was performed using the Kirby Bauer disc diffusion method on MuellerHinton agar medium. The following antibiotic agents were tested: Amoxicillin/Clavulanic acid $(20 / 10 \mu \mathrm{g})$, Ampicillin $(10 \mu \mathrm{g})$, Ceftriaxone $(30 \mu \mathrm{g})$, Chloramphenicol $(30 \mu \mathrm{g})$, Ciprofloxacin $(5 \mu \mathrm{g})$, Clindamycin $(2 \mu \mathrm{g})$, Erythromycin $(15 \mu \mathrm{g})$, and Trimethoprim/Sulfamethoxazole $(1.25 \mu \mathrm{g})$. Other antibiotic agents that were tested included: 


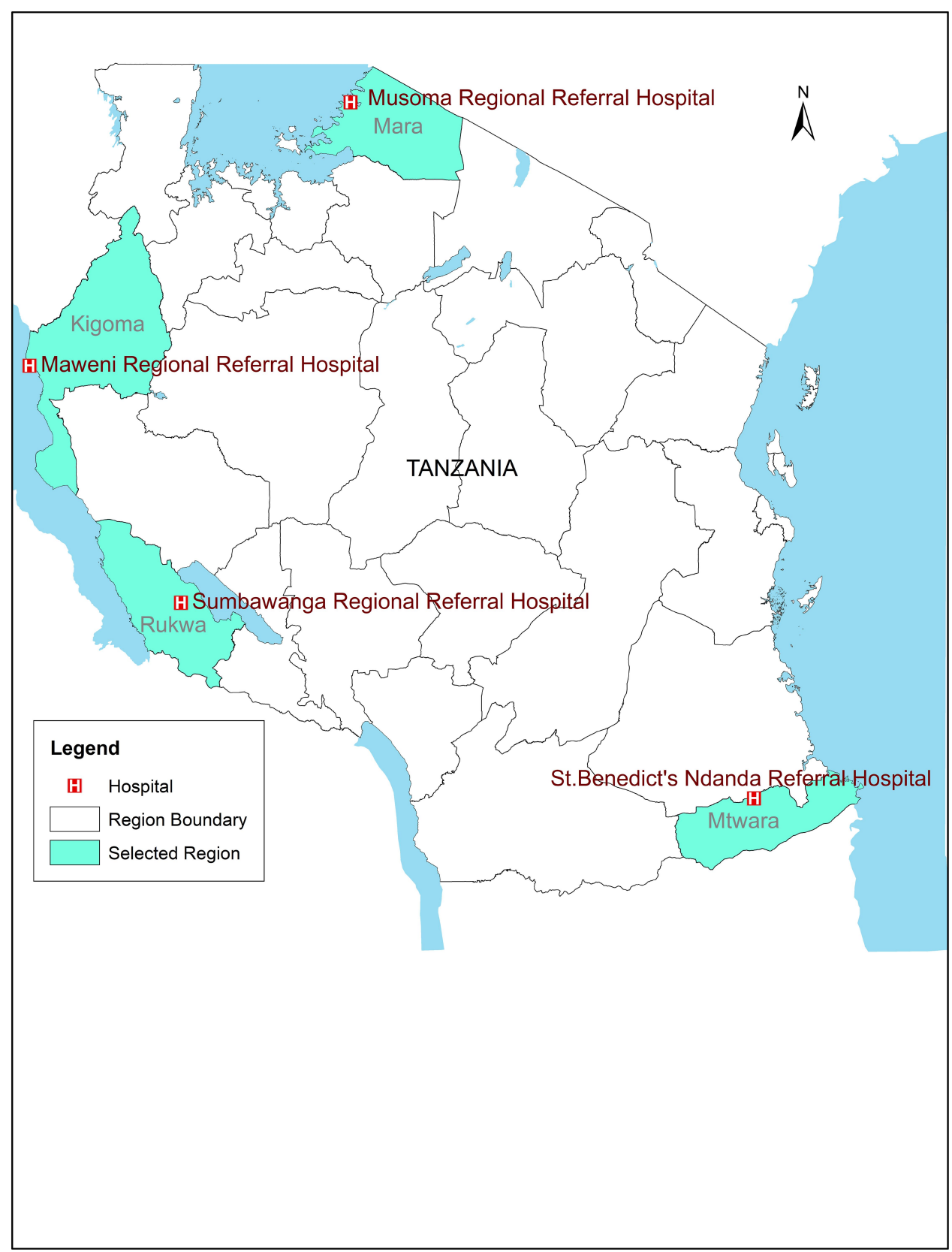

Figure I Map of the Republic of Tanzania showing geographic locations of the four study sites.

Gentamicin $(10 \mu \mathrm{g})$, Meropenem $(10 \mu \mathrm{g})$, Nitrofurantoin $(300 \mu \mathrm{g})$, and Tetracycline $(30 \mu \mathrm{g})$. Gram-negative bacteria E. coli and Klebsiella species were screened for ESBL production using Ceftazidime $(30 \mu \mathrm{g})$ and Cefotaxime $(30 \mu \mathrm{g})$. The double-disk synergy test for Ceftazidime $(30 \mu \mathrm{g})$, Cefotaxime $(30 \mu \mathrm{g})$, and Co-amoxicillin /Clavulanate $(20 / 10 \mu \mathrm{g})$ were used to confirm ESBL production. MRSA was detected using Cefoxitin $(30 \mu \mathrm{g})$ disc and isolates with a zone of inhibition of $\leq 21 \mathrm{~mm}$ were referred to as phenotypically confirmed MRSA. Reading and interpretation of zone sizes were as per CLSI guidelines. Isolates with intermediate or resistant results on antibiotic susceptibility were classified as resistant strains during data analysis. Laboratory activities were done at a respective hospital's laboratory as per the routine procedure. Participating laboratories were supported with reagents by the project and regular supportive supervision from the study research team.

\section{Quality Control}

Quality control strains K. pneumoniae ATCC 700603 and E. coli ATCC 25922 were used as positive and negative 
controls (respectively) for the detection of ESBL. E. coli ATCC 25922, S. aureus ATCC 25923 and other quality control strains were used for all laboratory methods in accordance with the CLSI guidelines.

\section{Data Management and Analysis}

Demographic information (ie, age, sex, and place of residence) was collected by laboratory technicians from the request forms and entered in an Excel spreadsheet. Data analysis was performed using STATA ${ }^{\mathrm{TM}}$ version 14.1 (Stata Corp LP, College Station, Texas, USA). Variables (ie, bacterial isolates, antibiotics susceptibility and demographic characteristics) were summarized as frequencies, percentages, medians, and inter-quartile ranges as deemed appropriate.

\section{Results}

\section{Patients Demographic Characteristics}

We processed a total of 2, 620 specimens during the observation period, but only $388(14.8 \%)$ were culturepositive and $19(0.7 \%)$ were discarded due to contamination. The patients' median (IQR) age was $28(12-44)$ years and females constituted 203 (52.3\%) of the participants. St. Benedict Ndanda Hospital contributed the majority of the specimens (see Table 1).

\section{Culture Results}

Most of the collected specimens were ear pus (28.6\%), urine $(24.0 \%)$, wound pus $(20.6 \%)$, stool $(15.0 \%)$, and blood (8.3\%). S. aureus was highly recovered from wound pus, ear pus, and blood (Table 2).

The most frequent isolate recovered was $S$. aureus (28.3\%), followed by E. coli $(15.2 \%)$, P. aeruginosa (10.6\%), P. mirabilis, V. cholerae 01 Ogawa, Klebsiella sp. and Streptococcus sp. S. aureus isolates were prevalent among males (54.5\%) and common in individuals aged 16-49 (48.6\%) while E. coli was predominant in females (79.7\%). P. aeruginosa was common in specimens from female patients (63.4\%). Both V. cholerae and Klebsiella sp. isolates were more prevalent among males (Table 3).

\section{Antibiotic Resistance Pattern of the Bacterial Isolates Identified}

Table 4 reports the antibiotic resistance patterns of bacterial isolates to commonly used antibiotics tested by the participating laboratories. Gram-negative bacteria were prevalent isolates in this study. Both gram-negative and-positive demonstrated a high level of resistance to widely used antibiotics tested. E. coli isolates were highly resistant to Ampicillin (100\%), Amoxicillin-Clavulanic Acid (75.0\%), Gentamicin (70.2\%), Tetracycline (70.2\%) and Ciprofloxacin (23 [42.6\%]), but least resistant to Ceftriaxone, Meropenem, and Nalidixic Acid. Only two isolates were screened for ESBL and both isolates were susceptible to Ceftazidime, hence no evidence of ESBL in the present study. Klebsiella spp. demonstrated resistance to Ampicillin (100\%), Amoxicillin-Clavulanic acid (90.9\%), Gentamycin (64.7\%), and Ceftriaxone (55.6\%), Ciprofloxacin (52.6\%). Among Gram-positive, the most prevalent $S$. aureus was highly resistant to Erythromycin (76.3\%), Gentamycin (54.0\%), Ciprofloxacin (40.0\%) and Clindamycin (34.9\%). In addition, 22/33 (66.7\%) of S. aureus isolates were resistant to Cefoxitin hence presumed MRSA.

\section{Discussion}

The emergence and pervasiveness of resistant bacteria represent a substantial global public health crisis. ${ }^{2}$ In the

Table I Demographic Characteristics of Study Participants $(\mathrm{N}=388)$

\begin{tabular}{|c|c|c|c|c|c|}
\hline \multirow{2}{*}{$\begin{array}{l}\text { Demographic } \\
\text { Characteristics }\end{array}$} & \multirow[t]{2}{*}{ Total } & \multicolumn{4}{|c|}{ Study Sites } \\
\hline & & Maweni $n=86$ & Musoma $n=85$ & Ndanda $n=\mid 58$ & Sumbawanga $n=59$ \\
\hline \multicolumn{6}{|l|}{ Sex } \\
\hline Male & $185(47.7)$ & $40(46.5)$ & $44(51.8)$ & $73(46.2)$ & $28(47.5)$ \\
\hline Female & $203(52.3)$ & $46(53.5)$ & $4 \mid(48.2)$ & $85(53.8)$ & $31(52.5)$ \\
\hline \multicolumn{6}{|l|}{ Age } \\
\hline $0-4$ & $46(12.0)$ & $8(9.3)$ & II (I3.8) & $23(14.7)$ & $4(6.8)$ \\
\hline $5-15$ & $65(17.0)$ & $22(25.6)$ & $10(12.5)$ & $21(13.4)$ & $12(20.3)$ \\
\hline $16-49$ & $19 \mid(50.0)$ & $43(50.0)$ & $4 \mid(5 I .3)$ & $77(49.0)$ & $30(50.9)$ \\
\hline $50+$ & $80(20.9)$ & $13(15.1)$ & $18(22.5)$ & $36(22.9)$ & I3 (22.0) \\
\hline Median (IQR) & $28(12,44)$ & $26(10,40)$ & $28.5(13.5,47)$ & $27(14,46)$ & $27(11,45)$ \\
\hline
\end{tabular}

Notes: Six participants had age missing; 5 were from Msoma and I from Ndanda. 
Table 2 Distribution of Identified Bacterial Isolates by Clinical Specimen

\begin{tabular}{|c|c|c|c|c|c|c|c|c|c|}
\hline \multirow[t]{2}{*}{ Isolate Type } & \multirow[t]{2}{*}{$\mathbf{N}$} & \multicolumn{8}{|c|}{ Specimen Type } \\
\hline & & Blood & Ear Pus & Urethral Pus & Vaginal Pus & Wound Pus & Stool & Urine & CSF \\
\hline Acinetobacter spp. & I & - & I (I00.0) & - & - & - & - & - & - \\
\hline Citrobacter spp. & 10 & - & $2(20.0)$ & $\mathrm{I}(10.0)$ & - & $3(30.0)$ & $3(30.0)$ & $\mathrm{I}(10.0)$ & - \\
\hline E. coli & 59 & - & $\mathrm{I}(\mathrm{I} .7)$ & $\mathrm{I}(\mathrm{I} .7)$ & $\mathrm{I}(\mathrm{I} .7)$ & $3(5.1)$ & $\mathrm{I}(\mathrm{I} .7)$ & $51(86.4)$ & $\mathrm{I}(\mathrm{I} .7)$ \\
\hline Enterobacter spp. & 5 & - & $3(60.0)$ & - & - & - & $2(40.0)$ & - & - \\
\hline K. oxytoca & 2 & - & - & - & - & - & - & $2(100)$ & - \\
\hline Klebsiella spp. & 20 & - & $5(25.0)$ & - & - & $4(20.0)$ & - & $\mathrm{II}(55.0)$ & - \\
\hline N. gonorrhoeae & 8 & - & - & $3(37.5)$ & $3(37.5)$ & - & - & $2(25.0)$ & - \\
\hline P. mirabilis & 27 & - & $13(48.2)$ & - & - & $10(37.0)$ & - & $4(14.8)$ & - \\
\hline$P$. aeruginosa & 41 & $4(9.8)$ & $27(65.9)$ & - & - & $9(22.0)$ & - & $I(2.4)$ & - \\
\hline Proteus spp. & 3 & - & - & - & - & - & - & $3(100.0)$ & - \\
\hline P. vulgaris & 5 & - & - & - & - & $4(80.0)$ & - & $\mathrm{I}(20.0)$ & - \\
\hline Pseudomonas spp. & 8 & - & $\mathrm{I}(\mathrm{I} 2.5)$ & - & - & $4(50.0)$ & - & $3(37.5)$ & - \\
\hline S. typhi & 4 & $I(25.0)$ & - & - & - & - & $3(75.0)$ & - & - \\
\hline Salmonella spp. & II & - & - & - & - & - & $\mathrm{II}(100)$ & - & - \\
\hline Serratia spp. & I & - & $\mathrm{I}(100.0)$ & - & - & - & - & - & - \\
\hline S. sonnei & 8 & - & - & - & - & - & $8(100)$ & - & - \\
\hline Shigella spp. & 4 & - & - & - & - & - & $4(100)$ & - & - \\
\hline S. aureus & 110 & 13(II.8) & $46(41.8)$ & $\mathrm{I}(0.9)$ & - & $43(39.1)$ & $2(1.8)$ & $5(4.5)$ & - \\
\hline S. saprophyticus & 4 & - & - & - & - & - & - & $4(100)$ & - \\
\hline Staphylococci (CoNs) & 5 & - & $2(40.0)$ & - & - & - & - & $3(60.0)$ & - \\
\hline Staphylococcus spp. & 5 & $I(20.0)$ & $3(60.0)$ & - & - & - & - & $I(20.0)$ & - \\
\hline S. pneumoniae & 4 & $I(25.0)$ & - & - & - & - & - & - & $3(75.0)$ \\
\hline S. aeuruginosa & I & - & $I(100)$ & - & - & - & - & - & - \\
\hline Streptococcus spp. & 18 & $12(66.7)$ & $5(27.8)$ & - & - & - & - & $\mathrm{I}(5.6)$ & - \\
\hline V. cholerae 01 ogawa & 24 & - & - & - & - & - & $24(100)$ & - & - \\
\hline Total & 388 & $32(8.3)$ & $\mathrm{III}(28.6)$ & $6(1.5)$ & $4(1.0)$ & $80(20.6)$ & $58(14.9)$ & $93(24.0)$ & $4(1.0)$ \\
\hline
\end{tabular}

present study, we evaluated the in-vitro susceptibility patterns of bacterial pathogens to widely prescribed antibiotics. Gram-negative bacteria constituted the majority of the isolates, this corroborates with previous studies in Tanzania. ${ }^{16,17}$ Predominant bacteria were $S$. aureus, E. coli, $P$. aeruginosa, $P$. mirabilis, $V$. cholerae 01 Ogawaa, Klebsiella sp., Streptococcus sp., Salmonella sp., Citrobacter sp., N. gonorrhoeae, S. aureus, E. coli, P. aeruginosa, Klebsiella spp., Salmonella spp., and Citrobacter spp. Most of these isolates are in the WHO's list of priority bacterial pathogens for research, discovery and development of new antibiotics. ${ }^{2}$ The pathogens exhibited a substantial high level of resistance to widely prescribed antibiotics such as Ampicillin, Amoxicillin-Clavulanic Acid, Erythromycin, Trimethoprim, Ceftriaxone, Tetracycline, Nalidixic Acid, and Chloramphenicol. Previous studies have shown a similar pattern of antibiotic resistance in Tanzania $^{16-18}$ and other parts of Africa. ${ }^{19}$
Ear pus, urine, wound pus, stool, and blood specimens were the most frequent clinical specimens analyzed. The presence of a large number of ear pus specimen points toward suppurative otitis diseases which are common in children and adolescents below 15 years especially in subSaharan Africa, ${ }^{20}$ and their transmission is linked to poor hygienic conditions. P. aeruginosa, S. aureus, Proteus spp., and Klebsiella spp. are the most cited causative agents for otitis in sub-Sharan Africa and are reported to exhibit a high level of resistance to multiple antibiotics. ${ }^{20}$ On the other hand, the majority of the participants were women of reproductive age, which explains the high number of urine specimens and E. coli processed in this study.

Resistance was also observed to third-generation cephalosporins (Ceftriaxone and Ceftazidime) and Clindamycin and Meropenem are among essential antibiotics reserved for use in tertiary hospitals listed in the WHO antibiotic stewardship programmes, ${ }^{21,22}$ suggesting that we are precariously nearing a point of treatment option 
Table 3 Distribution of Identified Bacterial Pathogens from Different Clinical Samples

\begin{tabular}{|c|c|c|c|c|c|c|}
\hline \multirow[t]{2}{*}{ Isolate } & \multicolumn{2}{|c|}{ Sex } & \multicolumn{4}{|c|}{ Age* } \\
\hline & Female & Male & $0-4$ & $5-15$ & $16-49$ & $50+$ \\
\hline Acinetobacter spp. & $I(100)$ & 0 & 0 & 0 & $I(100)$ & 0 \\
\hline Citrobacter spp. & $3(30.0)$ & $7(70.0)$ & $\mathrm{I}(10.0)$ & 0 & $8(80.0)$ & $I(I 0)$ \\
\hline E. coli & $47(79.7)$ & $12(20.3)$ & $4(6.8)$ & $3(5.1)$ & $33(55.9)$ & $19(32.2)$ \\
\hline Enterobacter spp. & $3(60.0)$ & $2(40.0)$ & 0 & 0 & $5(100)$ & 0 \\
\hline K. oxytoca & $I(50.0)$ & $I(50.0)$ & 0 & 0 & 0 & $2(100)$ \\
\hline Klebsiella spp. & $8(40.0)$ & $12(60.0)$ & 0 & $I(5.6)$ & $10(55.6)$ & $7(38.9)$ \\
\hline N. gonorrhoeae & $4(50.0)$ & $4(50.0)$ & 0 & $\mathrm{I}(\mathrm{I} 2.5)$ & $6(75.0)$ & $I(I 2.5)$ \\
\hline P. mirabilis & $14(5 \mid .9)$ & 13(48.2) & $2(7.4)$ & $3(I I .1)$ & 13(48.2) & $9(33.3)$ \\
\hline P. aeruginosa & $26(63.4)$ & $15(36.6)$ & $6(15.0)$ & $8(20.0)$ & $17(42.5)$ & $9(22.5)$ \\
\hline Proteus spp. & $I(33.3)$ & $2(66.7)$ & $I(33.3)$ & 0 & $I(33.3)$ & $I(33.3)$ \\
\hline P. vulgaris & $3(60.0)$ & $2(40.0)$ & 0 & 0 & $3(60.0)$ & $2(40.0)$ \\
\hline Pseudomonas spp. & $4(50.0)$ & $4(50.0)$ & $2(25.0)$ & 0 & $4(50.0)$ & $2(25.0)$ \\
\hline S. typhi & $2(50.0)$ & $2(50.0)$ & 0 & $2(50.0)$ & $2(50.0)$ & 0 \\
\hline Salmonella spp. & $4(36.4)$ & $7(63.6)$ & 0 & $4(36.4)$ & $6(54.6)$ & $I(9.1)$ \\
\hline Serratia spp. & $\mathrm{I}(100)$ & 0 & 0 & 0 & $I(100)$ & 0 \\
\hline S. sonnei & $4(50.0)$ & $4(50.0)$ & 0 & 0 & $7(87.5)$ & $I(I 2.5)$ \\
\hline Shigella spp. & $I(25.0)$ & $3(75.0)$ & $0(0.0)$ & $0(0.0)$ & $3(1.6)$ & $\mathrm{I}(\mathrm{I} .3)$ \\
\hline S. aureus & $50(45.5)$ & $60(54.6)$ & $18(16.8)$ & $22(20.6)$ & $52(48.6)$ & $15(14.0)$ \\
\hline S. saprophyticus & $3(75.0)$ & $I(25.0)$ & 0 & $I(25.0)$ & $3(75.0)$ & 0 \\
\hline Staphylococci (CoNs) & $2(40.0)$ & $3(60.0)$ & 0 & 0 & $3(60.0)$ & $2(40.0)$ \\
\hline Staphylococcus spp. & $4(80.0)$ & $I(20.0)$ & $2(40.0)$ & 0 & $3(60.0)$ & 0 \\
\hline S. pneumoniae & $\mathrm{I}(25.0)$ & $3(75.0)$ & $I(25.0)$ & $3(75.0)$ & 0 & 0 \\
\hline Streptococcus spp. & $7(38.9)$ & $I I(6 I . I)$ & $6(33.3)$ & $9(50.0)$ & $I(5.6)$ & $2(I I . I)$ \\
\hline V. cholerae 0I Ogawa & $9(37.5)$ & $15(62.5)$ & $3(12.5)$ & $8(33.3)$ & $8(33.3)$ & $5(20.8)$ \\
\hline
\end{tabular}

Note: *Six participants had missing age response.

failure. The use of third-generation cephalosporins is insufficiently controlled in Tanzania and a high resistance level has been described previously. ${ }^{16}$ The observed high rate of resistance is presumably because patients may have constantly pre-exposed to a wide variety of antibiotics including self-prescribing sub-optimal dosages before their referrals to tertiary hospitals.

As this study was conducted in hospitals located in borders, the spread of AMR across neighboring countries such as Kenya, Uganda, and Burundi are highly possible. This highlights the need for coordinated actions among stakeholders including the neighboring countries for effective measures in fighting infectious antibiotic resistance.

Gram-negative bacteria such as E. coli, P. aeruginosa, P. mirabilis, V. cholerae 01 Ogawa, Klebsiella spp., and Streptococcus spp. were prevalent, similar to earlier studies conducted in Tanzania. ${ }^{16-18}$ E. coli, and Klebsiella spp. were frequently found in urine specimens; the two are cited as the leading etiologies of urinary tract infections (UTI) especially among pregnant women. ${ }^{23,24}$ E. coli and Klebsiella spp. are the most important bacteria associated with ESBL-mediated resistance to multiple antibiotics, including carbapenems and cephalosporins - the most potent agents for treating multi-drug resistant bacteria. ${ }^{2}$ In our study, both isolates E. coli and Klebsiella spp. were highly resistant to many antibiotics tested include Ciprofloxacin, an antibiotic commonly used to treat UTI. P. mirabilis, which is also known to cause UTI, was less frequently recovered in urine, but abundant in the ear and wound swabs. The high observation of UTI causing bacteria in the current study can be described as a result of poor sanitation and hygiene practices. For better patient management, clinicians should prescribe antibiotics for UTI depending on whether the infection is uncomplicated (lower-tract UTI) or complicated (associated with a condition, such as a structural/functional abnormality of the genitourinary tract or the presence of an underlying disease). ${ }^{25}$

Cholera remains a major public health problem especially in sub-Saharan Africa, ${ }^{26,27}$ and during the implementation of this study, Tanzania was experiencing numerous waves of cholera outbreaks. Like most other 


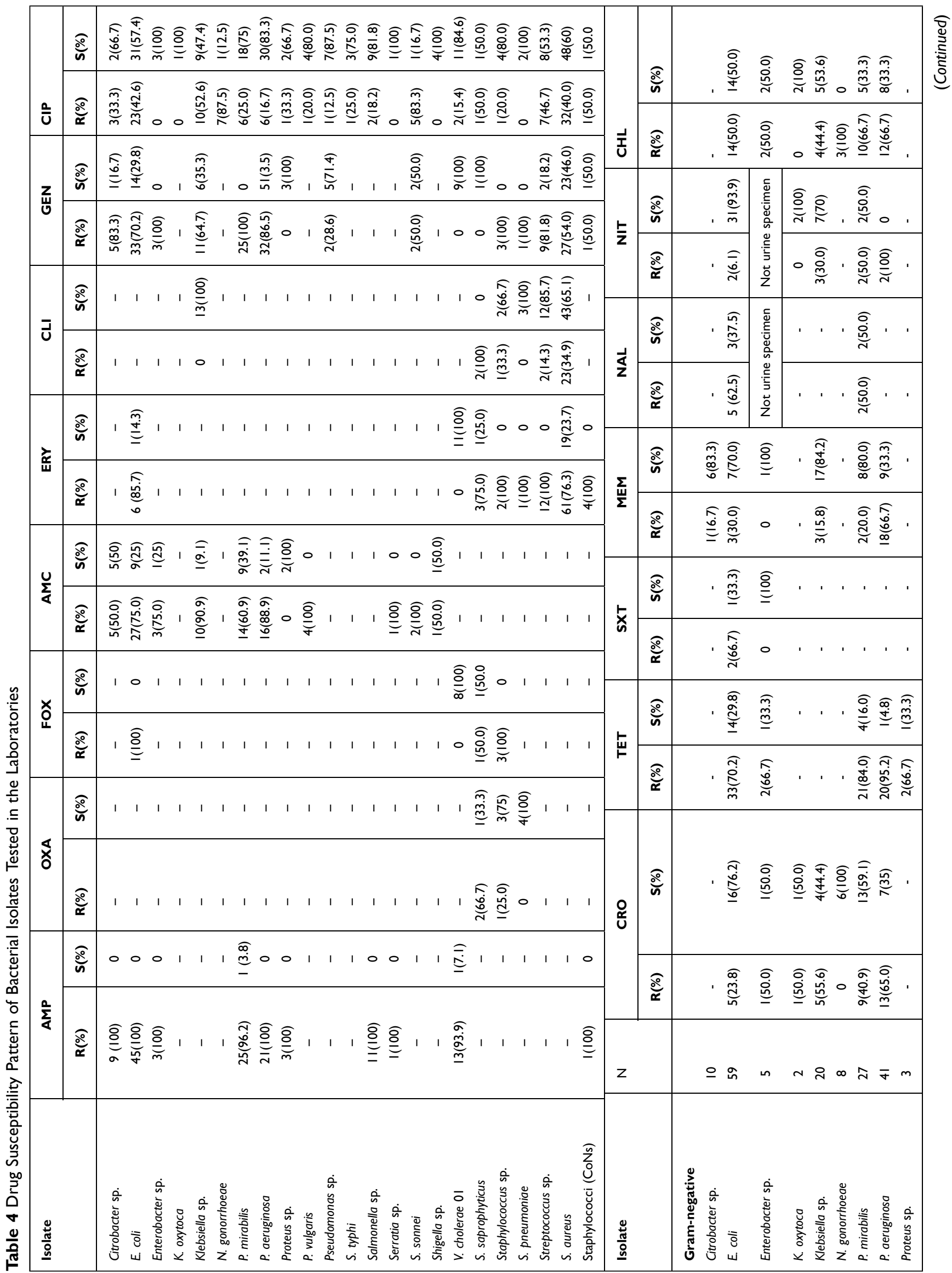




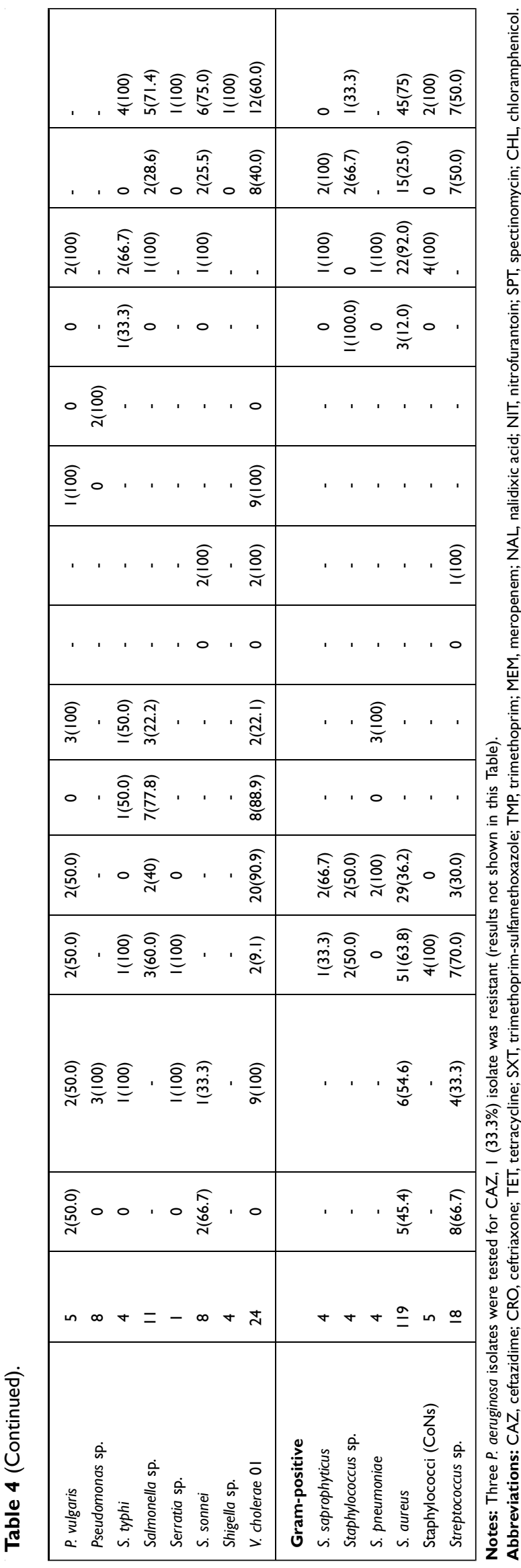

bacteria of clinical relevance, cholera is continuously becoming more resistant to a wide range of antibiotics. $^{26-28}$ In the present study, cholera isolates were highly resistant to Ampicillin, TrimethoprimSulfamethoxazole, Nalidixic Acid, Chloramphenicol, and least resistant to Ciprofloxacin. The isolates were, however, susceptible to widely used antibiotics for treatment of cholera (Tetracycline), Ceftriaxone, Meropenem, Gentamicin, Erythromycin, and Cefoxitin. As in the case of UTI, availability of clean and safe water sources, proper sanitation and hygiene, and public health education is critical in preventing/controlling the spread of $V$. cholerae in communities.

The majority of $P$. aeruginosa isolates were recovered from wound pus and ear pus and the pathogen was highly resistant to Ampicillin, Amoxicillin-Clavulanic Acid, Gentamicin, Ceftriaxone, Tetracycline, Nalidixic Acid, and Meropenem but more susceptibility to Ciprofloxacin. Resistance to Meropenem was $66.7 \%$, relatively higher than the $55.2 \%$ reported by Mikomangwa et al $(2020)^{18}$ and $19 \%$ in a study conducted at Bugando Medical Centre using isolates collected between 2012 and 2017. ${ }^{29}$ This suggests that $P$. aeruginosa is increasingly becoming resistant to antibiotics. $N$. gonorrhoeae was susceptible to Ceftriaxone but exhibited high resistance to Chloramphenicol (100\%) and Ciprofloxacin (87.5\%). High level of resistance to Azithromycin, Tetracycline, Ciprofloxacin, Penicillin, and to the injectable extendedspectrum cephalosporin Ceftriaxone have been described especially in regions where Gonorrhea is most prevalent. ${ }^{30}$ By 2017, treatment failure to third-generation cephalosporin antibiotics had been confirmed in at least 10 countries worldwide; South Africa, Australia, United Kingdom, Canada, Japan, Norway, France, Slovenia, Sweden, and Northern Ireland. ${ }^{30}$

S. aureus, a Gram-positive bacterium was the most common isolate that constituted nearly one-third of all bacterial isolates, mainly recovered from the ear and wound pus and blood specimens. Isolation of $S$. aureus in stool and urine was more likely due to skin contamination picked up during specimen collection. Of the isolates tested, (66.7\%) were resistant to Cefoxitin and classified as MRSA infection. This observation corroborates with that recently reported at Muhimbili National Hospital and Bugando Medical Centre (61\%), ${ }^{18}$ and those from other sub-Saharan Africa countries; Kenya (53.5\%), ${ }^{31}$ Rwanda $\left.(82 \%)^{32}\right)$ and Eretria $(72 \%){ }^{32}$ S. aureus isolates also exhibited resistance to Erythromycin, Tetracycline, and 
Gentamicin and moderate susceptibility to Ciprofloxacin, and Ceftriaxone. $S$. aureus isolates were mainly susceptible to Nalidixic acid, Clindamycin, and Chloramphenicol.

\section{Limitation}

Despite the current findings can be used for operational discussion on possible comprehensive national control programs on antimicrobial resistance, genotypic characterization of antibiotic resistance and virulence genes could have provided more information on the genetic profile and complement phenotypic methods. In addition, in some instances, fewer isolates were tested against specific antibiotics (eg, only two $E$. coli isolates were assessed for the presence of ESBL), hence hindering their generalizability.

\section{Conclusion}

Clinical isolates exhibited high resistance to most of the commonly used antibiotics. This emphasizes the need to strengthen national control programs such as routine antibiotic susceptibility testing and surveillance.

\section{Data Sharing Statement}

All important data and methods are reported in the main text. Additional datasets used and/or analyzed during the current study are available from the corresponding authors on reasonable request.

\section{Ethical Considerations}

The study was granted ethical clearance from the National Health Research Ethics Committee (NatHREC) of Tanzania with reference number NIMR/HQ/R.8a/Vol.IX/2706. As this study involved collected specimens from routine clinical practices, informed consent was waived by the NatHREC. We obtained the gateway permissions from the administrative authorities of each of the participating hospitals. Data access complied with relevant data protection and privacy regulations.

\section{Acknowledgments}

The authors would like to express deepest gratitude to Laboratory technicians and administrations of the four hospitals for their support during the implementation of this study.

\section{Author Contributions}

All authors made a significant contribution to the work reported, whether that is in the conception, study design, execution, acquisition of data, analysis, and interpretation; took part in drafting, revising, or critically reviewing the article. All authors gave final approval of the version to be published and agreed on the journal to which the article has been submitted; and agree to be accountable for all aspects of the work.

\section{Funding}

This study received financial support from the World Bank (soft loan) through the East African Public Health Laboratory Network (EAPHLN) project in Tanzania. Partial support was received from the Afrique OneASPIRE consortium, funded by the African Academy of Sciences (AAS) Alliance for Accelerating Excellence in Science in Africa (AESA), the New Partnership for Africa's Development Planning and Coordinating (NEPAD) Agency, the Wellcome Trust (107753/A/15/Z), and the UK government. The funders had no role in study design, data collection, analysis, preparation of the manuscript and decision to publish.

\section{Disclosure}

The authors declare no conflicts of interest for this work.

\section{References}

1. Leopold SJ, van Leth F, Tarekegn H, Schultsz C. Antimicrobial drug resistance among clinically relevant bacterial isolates in sub-Saharan Africa: a systematic review. J Antimicrob Chemother. 2014;69 (9):2337-2353. doi:10.1093/jac/dku176.

2. WHO. Prioritization of Pathogens to Guide Discovery, Research and Development of New Antibiotics for Drug Resistant Bacterial Infections, Including Tuberculosis. WHO; 2017.

3. Naylor NR, Atun R, Zhu N, et al. Estimating the burden of antimicrobial resistance: a systematic literature review. Antimicrob Resist Infect Control. 2018;7(1):58. doi:10.1186/s13756-018-0336-y.

4. O'Neill J. Antimicrobial Resistance: tackling a crisis for the health and wealth of nations 2014. Available from; https://wellcomecollection. org/works/rdpck35v. Accessed January 12, 2021.

5. Cantón R, Horcajada JP, Oliver A, Garbajosa PR, Vila J. Inappropriate use of antibiotics in hospitals: the complex relationship between antibiotic use and antimicrobial resistance. Enferm Infecc Microbiol Clin. 2013;31:3-11. doi:10.1016/S0213-005X(13)70126-5.

6. Mnyambwa PM, Kim D-J, Ngadaya ES, Kazwala R, Petrucka P, Mfinanga SG. Clinical implication of novel drug resistance-conferring mutations in resistant tuberculosis. Eur J Clin Microbiol Infect Dis. 2017;36:2021-2028. doi:10.1007/s10096-0173027-3.

7. Thomson KS. Extended-spectrum- $\beta$-lactamase, AmpC, and carbapenemase issues. J Clin Microbiol. 2010;48:1019-1025. doi:10.1128/ JCM.00219-10.

8. Madec JY, Haenni M, Nordmann P, Poirel L. Extended-spectrum $\beta$ lactamase/AmpC- and carbapenemase-producing Enterobacteriaceae in animals: a threat for humans? Clin Microbiol Infect. 2017;23:826-833. doi:10.1016/j.cmi.2017.01.013.

9. Boyle DP, Zembower TR. Epidemiology and Management of Emerging Drug-Resistant Gram-Negative Bacteria: extendedSpectrum $\beta$-Lactamases and Beyond. Urol Clin North Am. 2015;42 (4):493-505. doi:10.1016/j.ucl.2015.05.005. 
10. Laxminarayan R, Matsoso P, Pant S, et al. Access to effective antimicrobials: a worldwide challenge. Lancet. 2016;387:168-175. doi:10.1016/S0140-6736(15)00474-2.

11. Low A, Gavriilidis G, Larke N, et al. Incidence of Opportunistic Infections and the Impact of Antiretroviral Therapy among HIV-Infected Adults in Low- and Middle-Income Countries: a Systematic Review and Meta-analysis. Clin Infect Dis. 2016;62 (12):1595-1603. doi:10.1093/cid/ciw125.

12. Mhada TV, Fredrick F, Matee MI, Massawe A. Neonatal sepsis at Muhimbili National Hospital, Dar es Salaam, Tanzania; aetiology, antimicrobial sensitivity pattern and clinical outcome. BMC Public Health. 2012;12(1):1. doi:10.1186/1471-2458-12-904.

13. Maze MJ, Bassat Q, Feasey NA, Mandomando I, Musicha P, Crump JA. The epidemiology of febrile illness in sub-Saharan Africa: implications for diagnosis and management. Clin Microbiol Infect. 2018;24(8):808-814. doi:10.1016/j.cmi.2018.02.011.

14. Said Aboud RM. GARP-Tanzania Situation Analysis and recommendation| antibiotics use and resistance in Tanzania 2015. Available from: http://www.cddep.org/publications/garp_tanzania_situation_ analysis\#sthash.mqdm17im.dpbs. Accessed May 11, 2017.

15. Clsi. M. 100 Performance Standards for Antimicrobial Susceptibility Testing. 27th ed. 2017.

16. Kumburu HH, Sonda T, Mmbaga BT, et al. Patterns of infections, aetiological agents and antimicrobial resistance at a tertiary care hospital in northern Tanzania. Trop Med Int Heal. 2017;22 (4):454-464. doi:10.1111/tmi.12836.

17. Moremi N, Claus H, Mshana SE. Antimicrobial resistance pattern: a report of microbiological cultures at a tertiary hospital in Tanzania. BMC Infect Dis. 2016;16(1):756. doi:10.1186/s12879-016-2082-1.

18. Mikomangwa WP, Bwire GM, Kilonzi M, et al. The Existence of High Bacterial Resistance to Some Reserved Antibiotics in Tertiary Hospitals in Tanzania: a Call to Revisit Their Use. Infect Drug Resist. 2020; Volume 13:1831-1838. doi:10.2147/IDR.S250158.

19. Tadesse BT, Ashley EA, Ongarello S, et al. Antimicrobial resistance in Africa: a systematic review. BMC Infect Dis. 2017;17(1):1-17. doi:10.1186/s12879-017-2713-1.

20. Tesfa T, Mitiku H, Sisay M, et al. Bacterial otitis media in sub-Saharan Africa: a systematic review and meta-analysis. $B M C$ Infect Dis. 2020;20(1):1-12. doi:10.1186/s12879-020-4950-y.

21. WHO. World Health Organization Model List of Essential Medicines. WHO; 2019.

22. Ministry of Health, Community Development, Gender, Elderly and Children (MoHCDEC) (Tanzania): Standard treatment guidelines and essential medicines list for children and adolescents. 2018.
23. Alemu A, Moges F, Shiferaw Y, et al. Bacterial profile and drug susceptibility pattern of urinary tract infection in pregnant women at University of Gondar Teaching Hospital, Northwest Ethiopia. BMC Res Notes. 2012;5.

24. Moyo SJ, Aboud S, Kasubi M, Maselle SY. Bacterial isolates and drug susceptibility patterns of urinary tract infection among pregnant women at Muhimbili National Hospital in Tanzania. Tanzan J Health Res. 2010;12(4):233-236. doi:10.4314/thrb.v12i4.52997.

25. Tan CW, Chlebicki MP. Urinary tract infections in adults. Singapore Med J. 2016;57(09):485-490. doi:10.11622/smedj.2016153.

26. Hounmanou YMG, Leekitcharoenphon P, Kudirkiene E, et al. Genomic insights into Vibrio cholerae O1 responsible for cholera epidemics in Tanzania between 1993 and 2017. PLoS Negl Trop Dis. 2019;13:e0007934. doi:10.1371/JOURNAL.PNTD.0007934.

27. McCrickard LS, Massay AE, Narra R, et al. Cholera mortality during urban epidemic, Dar es Salaam, Tanzania, August 16, 2015January 16, 2016. Emerg Infect Dis. 2017;23(13):S154-7. doi:10.3201/eid2313.170529.

28. Urassa WK, Mhando YB, Mhalu FS, Mjonga SJ. Antimicrobial susceptibility pattern of Vibrio cholerae O1 strains during two cholera outbreaks in Dar es Salaam, Tanzania. East Afr Med J. 2000;77 (7):350-353.

29. Mushi MF, Mshana SE, Imirzalioglu C, Bwanga F. Carbapenemase genes among multidrug resistant gram negative clinical isolates from a tertiary hospital in Mwanza, Tanzania. Biomed Res Int. 2014;2014:2014. doi:10.1155/2014/303104.

30. Wi T, Lahra MM, Ndowa F, et al. Antimicrobial resistance in Neisseria gonorrhoeae: global surveillance and a call for international collaborative action Summary points 2017. PLoS Med. 2017. 14(7): e1002344. doi:10.1371/journal.pmed.1002344.

31. Wangai FK, Masika MM, Maritim MC, Seaton RA. Methicillinresistant Staphylococcus aureus (MRSA) in East Africa: red alert or red herring? BMC Infect Dis. 2019;19(1):596. doi:10.1186/s12879019-4245-3.

32. Garoy EY, Gebreab YB, Achila OO, et al. Methicillin-Resistant Staphylococcus aureus (MRSA): prevalence and Antimicrobial Sensitivity Pattern among Patients - A Multicenter Study in Asmara, Eritrea. Can J Infect Dis Med Microbiol. 2019;2019:2019. doi:10.1155/2019/8321834.
Infection and Drug Resistance

\section{Publish your work in this journal}

Infection and Drug Resistance is an international, peer-reviewed openaccess journal that focuses on the optimal treatment of infection (bacterial, fungal and viral) and the development and institution of preventive strategies to minimize the development and spread of resistance. The journal is specifically concerned with the epidemiology of antibiotic resistance and the mechanisms of resistance development and diffusion in both hospitals and the community. The manuscript management system is completely online and includes a very quick and fair peerreview system, which is all easy to use. Visit http://www.dovepress.com/ testimonials.php to read real quotes from published authors. 